\title{
Changes in Erotic Expression in Women with Fibromyalgia
}

\author{
Juan Pablo Sanabria Mazo 1 (D) https://orcid.org/0000-0003-1688-435X \\ Mariana Gers Estrada ${ }^{1}$ (D) https://orcid.org/0000-0002-0614-3518
}

\begin{abstract}
The scientific literature indicates that chronic pain influences the sex life of women. The objective of this research was to describe the changes in the erotic expression of a group of women with fibromyalgia. For this, a qualitative study of interpretive phenomenological design was conducted in which 15 women were interviewed in depth. Some participants said that the appearance of the disease was an opportunity to strengthen their relationship. Others said that their partners' indifference and skepticism about the disease, as well as the lack of understanding in the sexual sphere, acted as barriers in the relationship. Sexual intercourse was perceived as an obligation associated with gender or as an irrelevant dimension. Sensory stimulation and preliminary sexual play were strategies that allowed them to adjust and promote mutual enjoyment. The position taken by women in the face of disease influences the erotic expression.
\end{abstract}

Keywords: fibromyalgia, sexuality, pain, women, qualitative research

\section{Alterações na Expressão Erótica em Mulheres com Fibromialgia}

Resumo: A literatura científica indica que a dor crônica influencia a vida sexual das mulheres. O objetivo desta investigação foi descrever as mudanças na expressão erótica de um grupo de mulheres com fibromialgia. Para isso, foi realizado um estudo qualitativo com delineamento fenomenológico interpretativo no qual foram realizadas entrevistadas aprofundadas com 15 mulheres. Algumas participantes disseram que a aparição da doença foi uma oportunidade para fortalecer seu relacionamento. Outras afirmaram que a indiferença e o ceticismo de seus parceiros diante da doença, bem como a falta de compreensão na esfera sexual, atuaram como barreiras no relacionamento. As relações sexuais foram percebidas como uma obrigação associada ao gênero ou como uma dimensão irrelevante. A estimulação sensorial e o jogo sexual preliminar foram estratégias que lhes permitiram ajustar e promover o prazer mútuo. A postura assumida pelas mulheres diante da doença influencia a expressão erótica.

Palavras-chave: fibromialgia, sexualidade, dor, mulheres, pesquisa qualitativa

\section{Cambios en la Expresión Erótica en Mujeres con Fibromialgia}

Resumen: La literatura científica indica que el dolor crónico influye en la vida sexual de las mujeres. El objetivo de esta investigación fue describir los cambios en la expresión erótica de un grupo de mujeres con fibromialgia. Para esto, se realizó un estudio cualitativo de diseño fenomenológico interpretativo en el que se entrevistaron en profundidad a 15 mujeres. Algunas participantes aseguraron que la aparición de la enfermedad fue una oportunidad para fortalecer su relación. Otras que la indiferencia y el escepticismo de sus parejas ante la enfermedad, así como la incomprensión en el ámbito sexual, actuaron como barreras en la relación. Los encuentros sexuales se percibieron como una obligación asociada al género o como una dimensión irrelevante. La estimulación sensorial y el juego sexual preliminar fueron estrategias que les permitieron ajustarse y promover el disfrute mutuo. La postura que asumen las mujeres frente a la enfermedad influyen en la expresión erótica.

Palabras clave: fibromialgia, sexualidad, dolor, mujeres, investigación cualitativa

\section{${ }^{1}$ Pontificia Universidad Javeriana, Cali, Colombia}

This paper is derived from the final degree work of the first and second authors under the supervision of Diego Emiro Correa Sánchez, defended in 2016, in the Pontificia Universidad Javeriana. Support: Facultad de Humanidades y Ciencias Sociales and the Research Group Salud y Calidad de Vida of the Pontificia Universidad Javeriana de Cali, Colombia.

Correspondence address: Juan Pablo Sanabria Mazo. Pontificia Universidad Javeriana. Facultad de Humanidades y Ciencias Sociales, Calle 18 $\mathrm{n}^{\mathrm{o}}$ 118-250, Cali, Colombia. E-mail: jpablo.sanabria@outlook.com
In recent years several studies have identified a high prevalence of sexual dysfunction in women diagnosed with fibromyalgia (Ambler, Williams, Hill, Gunary, \& Cratchley, 2001; Ferreira et al., 2013; Yilmaz, Yilmaz, Polat et al., 2012; Yilmaz, Yilmaz, \& Erkin, 2012). Specialists in the field have pointed out that the widespread pain and the emotional alterations derived from this disease directly influence the arousal, frequency and sexual desire of these women 
(Ülker, Çakır, Yalçınkaya, Demirdal, \& Toraman, 2013). Although the etiology of sexual dysfunctions in patients with chronic pain has been poorly addressed, researchers say that since it is a multifactorial problem, some of the influences are general to all dysfunctions and others specific to each disorder (Hernández-Petro \& Cardona-Arias, 2014; Kalichman, 2009; Shaver, Wilbur, Robinson, Wang, \& Buntin, 2006; Soriano, Monsalve, Gómez-Carretero, \& Ibáñez, 2012; Tawadros et al., 2013; Triviño-Martínez, Solano-Ruiz, \& Siles-González, 2014).

At present, the main causes that have been associated in the scientific literature to these alterations are pharmacological, physical and psychological. Regarding the pharmacological, it has been reported that there are various medications, most antidepressants, which can affect the sexual functioning of these women. On the other hand, physical fatigue and muscle pain, linked to intolerance to exercise, have been related as the physical causes that most influence sexual dysfunctions. Hypersensitivity to pain affects sexual relationships and increases the feeling of tiredness. This situation, in turn, increases the possibilities of progressive avoidance of pleasant activities and, therefore, rejection of these encounters (Blázquez, Alegre, \& Ruiz, 2009; Osborn \& Smith, 2006; Prins, Woertman, Kool, \& Geenen, 2006; Sanabria \& Gers, 2018).

In a research carried out in England, Ambler et al. (2001) found that at the time of intercourse, the patients showed an increase in pain that was associated with sexual dysfunction and with the pain threshold. Dyspareunia and vaginismus were one of the complaints reported most frequently by patients with chronic pain (Kool, Woertman, Prins, Van Middendorp, \& Geenen, 2006; Ülker et al., 2013). The results of the study conducted by Shaver et al. (2006) in the United States suggested that women with fibromyalgia register a significant decrease in orgasm, self-pleasure, sexual activity and satisfaction, as well as vaginal dryness during penetration. Studies conducted in the Netherlands, such as those by Kool et al. (2006) and Prins et al. (2006), and in the United States, like that of Schlesinger (1996), indicated that sexual dysfunctions were linked more to psychological than physical factors, since there is empirical evidence that the impact of pain in sex life depends on the coping styles of each person.

In a systematic review conducted by Kalichman (2009) it was reported that the presence of mood disorders in patients with chronic pain was one of the psychological factors that most often caused loss of sexual desire and decreased pleasure. Anxiety, sexual abuse, low self-esteem, lack of understanding, history of abuse and lack of support from partners have been factors that have also been related to these alterations in the sexual response (Orellana et al., 2008). In contrast, Shaver et al. (2006) in the United States and Tikiz et al. (2005) in Turkey identified that the widespread pain in fibromyalgia is associated with sexual dysfunction and that the coexistence of major depression does not have any additional negative effect on sexual functioning. Although anxiety and depression are linked to sexual dysfunctions in women with fibromyalgia, it has been found that pain is the factor that most influences this difficulty (Shaver et al., 2006).

Ryan, Thwaites and Dawes (2012) in England found that about $80 \%$ of women diagnosed with fibromyalgia claim to have difficulties during their sexual relations. In this regard, Prins et al. (2006) stated that the psychological component is the one that most affects the sexual response cycle. On the other hand, García-Padilla, García-Padilla, Ballesteros de Valderrama and Novoa-Gómez (2003) in Colombia stated that the loss of sexual interest of patients with chronic diseases could be a consequence of the constant stress caused by the loss of autonomy for being sick. According to the findings obtained, the problems in the relationship are presented, therefore, when there is difficulty in understanding the clinical picture of the partner, who acts in a reciprocal way in relation to the feeling of frustration, guilt or rejection.

In this order of ideas, the lack of social support or dissatisfaction with the partner influence the physical and mental health of these women. In their study, Kool et al. (2006) concluded that although the support of the partner and the perceived satisfaction of the relationship contribute to the coping of fibromyalgia, the insistence of the partner in the sexual field can become a risk factor to increase the sensation of pain. As evidenced in studies carried out in Sweden, the appearance of the disease necessarily implies that the members of the couple develop adjustments in the dynamics of their relationship that allow them to resolve the difficulties that arise (Juuso, Skar, Olsson, \& Söderberg, 2014; Söderberg, Strand, Haapala, \& Lundman, 2003). The lack of adjustment can turn the partner into a source of stress and anxiety, rather than a point of support.

In other studies it was found that the thoughts of guilty reported by women were related to the decrease in sexual frequency and to the perception of inability to fulfill the sexual expectations of their partners (Ericksson \& Svedlund, 2006; García-Padilla et al., 2003; Loaring, Larkin, Shaw, \& Flowers, 2015; Rodham, Rance, \& Blake, 2010; Sanabria \& Gers, 2019). In this regard, Blásquez, Alegres and Ruiz (2009) in the United States and Orellana et al. (2008) in Spain found that women with chronic diseases said they could live the rest of their lives without having sex. The negative sexual constants were interpreted by their partners as a rejection and not as a manifestation of the disease. These barriers in the communication processes implied, in some cases, the rupture, the distancing between the members of the couple, the conflicts and the discriminations (Paulson, Norberg, \& Söderberg, 2003; Ryan et al., 2012; Schlesinger, 1996). The communication, therefore, became an obstructive or dynamic source of the couple's relationship (Bazzichi et al., 2012; Del Rio-González, García-Palacios, \& Botella-Arbona, 2014).

Ostrander (2009) in the United States said that after being diagnosed with chronic disease these women had enriched their sexuality with erotic practices that included sensuality, affection and intimacy. As a result of the adjustments derived from the disease, the participants affirmed that they learned to feel pleasure without feeling guilty for resorting to other 
sexual practices that did not focus on genitality and orgasm. The changes that arose due to the disease caused both women and their partners to strengthen the erotic dimension of their sexuality. The appearance of the disease was presented as an opportunity for both members to focus their attention on the mutual pleasure of the couple.

Although during the last decade there has been a growing interest in researching the implications that fibromyalgia has on sexual functioning, no research so far has had as its central purpose to understand the changes that this disease has in the erotic expression of the women. This study contributes, therefore, to diminishing a gap: (a) conceptual, because most of the research on the subject has focused on researching the influence of fibromyalgia on women's sex life from the perspective of the partner (Ericksson \& Svedlund, 2006; Paulson et al., 2003; Söderberg et al., 2003), in exploring the sexuality of the participants in a general way (Loaring et al., 2015; Osborn \& Smith, 2006; Rodham et al., 2010) or to emphasize more in the difficulties than in the adjustments made by couples to cope with the changes (Bazzichi et al., 2012; Kool et al., 2006; Prins et al., 2006; Shaver et al., 2006); and (b) methodological, because existing research in the literature has prioritized the exploration of this problem from an exclusively quantitative perspective in which the experience of sexuality was limited to the reduction of the frequency of sexual practices (Ambler et al., 2001; Ferreira et al., 2013; Yilmaz, Yilmaz, Polat, et al., 2012).

The lack of qualitative research on this subject justifies the relevance of exploring the sexual changes derived from fibromyalgia as a public health problem. For this reason, it is necessary to conduct studies that seek to recognize the implications of the disease in the erotic expression of women with their partners, understanding, in any case, these interactions as a dimension of sexuality that transcends genitality and sexual functioning. The main purpose of this research was, therefore, to describe the changes in erotic expression in women with fibromyalgia. The specific objectives of this study were: (a) to know the role of the disease in the couple's relationship, (b) to understand the changes in the erotic expression as a consequence of the diagnosis and (c) to identify the strategies used by the couple to face these changes in its sex life. In this researching, erotic expression was understood as well as the potential that women have to experience sexual pleasure as well as their capacity to generate subjective responses to sexual desire, arousal and orgasm.

\section{Method}

This research was carried out from a qualitative approach of interpretive phenomenological design, to the extent that this approach allows to describe the meaning of the experiences of the participants of their reality and recognizes the constructive function of the researcher in the interpretation of the phenomenon (Willig, 2013). The advantages of choosing this methodological design were that, on the one hand, they made it possible to approach the experiences as experienced by the participants and, on the other hand, that the constant reflection and theoretical revision was oriented to diminish the biases in the interpretation and to enrich the analysis.

\section{Participants}

The selection of the participants was done intentionally and was determined by the saturation criterion. This meant that the number of participants was gradually shaped according to the collection and interpretation of the data, and that the researchers were in constant theoretical, conceptual and methodological reflection during the research. In total, 15 women diagnosed with fibromyalgia participated, aged between 23 and 60 years $(M=43.2 ; S D=10.7)$. The average time elapsed since the diagnosis was communicated ranged from 2 to 20 years $(M=8.26 ; S D=7.43) .66 \%$ of the participants were married and $26 \%$ in free union. On average, they were with their partner between 2 and 35 years $(M=20.06 ; S D=11.12)$. The predominant levels of schooling were higher $(66 \%)$ and basic $(34 \%)$ education. $54 \%$ of them developed their work as housewives. Regarding their socioeconomic status, $20 \%$ belonged to the low level (stratum 1 and 2), 40\% to the medium (stratum 3 and 4) and $40 \%$ to the high (stratum 5 and 6 ).

As criteria for inclusion, it was taken into account that the participants: (a) were diagnosed with fibromyalgia for more than a year, (b) they were in a relationship for a period of not less than two years and (c) their ages will range between 20 and 60 years, being the age range of highest prevalence of the disease.

\section{Instruments}

In-depth interview. This technique allowed to understand the phenomenon from the interpretation of the participants. The guide of questions used had the validation of four expert judges in the subject, who verified the pertinence, the coherence and the writing of the questions, according to the objectives of the research and the categories of analysis. Based on the comments made by the judges and the application of a pilot interview, the questions that made up the final guide of the interview were adjusted. The categories of analysis were: (a) impact of the disease on the relationship, (b) changes in erotic expression and (c) sexual adjustment strategies. The choice of categories and subcategories was made based on both the experiences reported by the study population and the conceptual references identified in the review of the literature and the objectives proposed in the research.

\section{Procedure}

Data collection. The researchers contacted private health entities in Cali (Colombia), specialized in the management of chronic pain, to request authorization to access the study population. At the time of selecting the participants, the researchers made sure that they met the established inclusion 
criteria and that, once the scope of the study was known and accepted, they signed the informed consent. The interviews were conducted, between September 2015 and February 2016, in a private office. Depending on the needs of each interview, additional in-depth sessions were scheduled. This decision was linked to the established saturation principle. The interviews lasted approximately one hour and a half.

Data analysis. The interviews were transcribed in textual form and then analyzed according to the categories with the support of the ATLAS.ti program (version 7.5). To reduce possible biases in the interpretation, the analysis of the data was carried out by each of the researchers, based on the study categories and following the scheme of organization, segmentation and correlation necessary to achieve saturation (Willig, 2013). The triangulation by researchers was achieved through the Consensual Qualitative Research (CQR) technique. This made it possible to broaden the eyes of the researchers, as well as to facilitate the systematic comparison in the analysis. Recognizing the importance of the views of the interpreters in the phenomenon of study, during the process of data collection the researchers performed an exercise in reflexivity to recognize the influence of their subjective realities on the phenomenon of study.

\section{Ethical Considerations}

This research was approved by the corresponding instances of the university and was guided by Resolution No. 008430 of 1993 of the Ministry of Health that sets out the scientific, technical and administrative standards for health research with human beings in Colombia.

\section{Results}

\section{Impact of the Disease on the Relationship}

At the time when the doctors informed the participants of their diagnosis, they reported feeling uncertainty, hopelessness and fear regarding their future. The communication of the results of the exams was an unexpected news that involved a high emotional impact. The diagnosis allowed them to end the uncertainty and free themselves from the beliefs they had in relation to what was happening with their body. The appearance of the pain generated feelings of anger, impotence and sadness, as well as a feeling of exhaustion that extended during the day and that resulted in a decrease in physical and social activities.

Stability, mutual knowledge, reciprocity, intimacy and perceived maturity in the relationships of some of them helped their partners become a source of support. Others, however, highlighted that the previous conflicts of the couple had added to the conflicts arising from the disease: "has been very closed with my disease and that has hurt me greatly ... I've realized that I have to think only of myself' (Beatriz, 39 years old). In the time they shared with their partners, they usually attended social gatherings; however, they stated that the appearance of pain in their lives had significantly interfered with their activities as a partner.

In face of these changes, some said they had felt understanding on the part of their partner. Others claimed that although the pain was present, they tried to satisfy their partners and not give up their pleasurable activities. Although their partners generally offered their help, they often tended to downplay the importance of the disease or be skeptical of their pain.

I would like him to give more importance to my disease; I know he sees this as something unreal ... He has shown me that this does not interest him; when I get sick, I cannot tell you that I'm like this because of fibromyalgia because she gets angry (Violeta, 45 years old)

The support provided by their partners was valued as a manifestation of the love they felt for them. The accompaniment of their partners made it easier for them to cope with their condition and the manifestations of affection made them feel that the partners were able to connect with their pain.

Since I have fibromyalgia, he has become too sensitive; if I cry, he cries with me. That makes me feel accompanied, that I think he understands my pain ... Sometimes he gets so bad for my pains, that it's my turn to console him and tell him that everything will turn out well (Estela, 37 years old)

Participants reported that their partners showed their support with gestures such as cold compress, giving them massages, accompanying them to the doctor, getting their medications or doing housework. However, the excessive support of their partners against their daily limitations, caused them to feel overprotected. In this sense, they felt that the relationship was unbalanced because the care behaviors of the couple focused exclusively on them.

I feel the weak part of the relationship, the person that should be taken care of . . . I know he loves me, but sometimes I do not know if he sees me as a 'poor person that he has to take care of', with a feeling of regret ... I want you to see me in my place, at the same level, and be aware that I can do my things (Sofía, 23 years old)

The lack of understanding they perceived from their partners sometimes led to conflicts between them.

When he saw me with pain, he told me that he did not understand why I complained so much . . . So, when something hurts him, I do the same thing, I tell him that what he has is not any disease. There I take advantage so that he feels the same thing that makes me feel with his words (Diana, 60 years old) 
Upon knowing the diagnosis, many claimed to have proposed to their partner to separate because they felt it was unfair that they had to live with a person in these conditions.

I told him to get comfortable, to look for his space because it was not fair that he was linked to a person with this disease ... Since I told him, a certain distance was generated, although he understood that at that moment I was frustrated and that I said it to set limits and not generate burdens (Natalia, 32 years old)

The position assumed by their partners after their diagnosis caused many of these women to decide to focus exclusively on their satisfaction. In this sense, they affirmed feeling overwhelmed when perceiving that they were always the ones who had to make sacrifices for the benefit of the relationship. Others mentioned that fears had arisen regarding the separation of their partners and in front of the limitations to share with them. The crises that they lived as a couple were interpreted as moments in which love was put to the test or opportunities to strengthen their feelings towards the other. Participants who conceived of their relationship as routine and unstable highlighted that factors such as the disease, lack of spaces in the life as a couple and the appearance of conflicts contributed to the erosion of the relationship.

In general, the topics of conversation with the partner were related to home, work and daily life issues. Some highlighted that the disease became a taboo topic that they preferred to avoid talking with their partners. The main reasons why they preferred to silence their partner about this pain were not to show vulnerability, not to worry them, to prevent comments, to avoid overprotection and not to overload their partner with their complaints: "if I tell him that I am bad for these pains, he begins to ask me if I already took the, as well as if it was a child. Then no, I better keep quiet and do not say anything" (Violeta, 45 years old). In other cases, hiding their pain allowed them to prevent the appearance of possible conflicts. For this reason, many decided to express only what they felt when the pain exceeded the limits. The reason why they decided to silence their pain was because they put themselves in the place of their partners and understood what they could feel when listening to a person who was always complaining about her / his pain.

Get up every day and hear that it is hurting me here or there, I know it must be exhausting. It is enough that I must deal with this daily to make another person deal with the same thing . . . I know it's difficult and that's why I always try to show a good face and avoid him knowing that it hurts me (Natalia, 32 years old)

\section{Changes in Erotic Expression}

The participants assured that they showed affection to their partner through the physical contact, words, details and leisure activities they did together. Eventually both members of the couple learned to know the different ways through which each one demonstrated love. However, because of fibromyalgia, most perceived an imbalance in the way in which the members of the couple expressed their affection.

I believe that he is more aware of me than I of him ... I feel terrible for not being able to be more affectionate . . . but I know that this is because of the pain, because of the anguish that I have all the time (Lina, 54 years old)

The pain they felt acted as a barrier in the relationship and caused their partners to become more distant in physical contact for fear of hurting them.

When I am in such intense pain, I get a bad temper and tell him to leave me alone, that I do not want to be with anyone, nor with myself . . . By the pain I get bad and insult him without him deserving it (Violeta, 45 years old)

As a result of fibromyalgia many experienced changes in their intimate life as a partner. The changes that occurred in her sex life were associated with lack of lubrication, lack of sexual desire, pain, fatigue and irritability.

I do not feel pleasure in anything ... The pain is so horrible that I cannot get excited. That pain occurs all the time and is so impressive that it takes away the desire for everything. It's just me opening my legs and I am already starting to feel pain (Angélica, 41 years old)

The main changes at sexual level were the decrease in the frequency of sexual relations, the lack of sexual desire and the difficulties to experience orgasms.

We were very sexually active, but with the thousands of pains I feel now that has changed abruptly; we no longer have weekly sex, now we have sex, at most, once a month. That has been one of the main changes in our relationship and I understand that this is difficult for us, especially for him (Beatriz, 39 years old)

In addition, most affirmed the changes of position that they made during sexual activity caused them pain: "changing positions during our relationships hurts a lot; before I did not have that problem, now it hurts me every time we do something out of the ordinary, when we try to innovate" (Sofía, 23 years old). Others described how their fear of pain had become a barrier to connecting with pleasure: "when you have a condition like this, what you are looking for is to avoid everything that increases your pain and if one of those things is to have sexual relations, because you start to have fright, to reject them" (Natalia, 32 years old). The pain and lack of desire they felt when having sex with their partners 
caused some to develop strategies to avoid or postpone these meetings in a covert way.

It is not always because of the pain, sometimes it is also due to the lack of desire that one decides to fall asleep ... He often looks for me, but I have no desire, so I tell him that my head is hurting a lot (Alejandra, 46 years old)

One participant stated that she had decided to pretend the pleasure she felt during sex to prevent her partner from feeling bad.

The pain was generating a lot of frustration ... Time passed and passed and the thing is that I expected him to realize that I was not enjoying, that I was in pain ... He asked me if I was okay, if I was enjoying myself and I said yes, even though I was really pretending (Camila, 29 years old)

While some decided to openly express to their partners their decision not to want to have relationships when they were in pain, others decided to reserve displeasure to avoid the feeling of rejection by both parties.

I said to him no. I was too angry that I did not understand that everything hurts, that the last thing I want is to have sex. One day I made the decision to tell him that I did not want to have sex because I did not feel well and that it was something I did not know if I was going to change (Violeta, 45 years old)

The difficulties they had in expressing reluctance to have sexual relations generated discomfort and anger and long-term conflicts with their partners.

I said that it is better to leave him free, because, if not, at some point he will go with a pair of legs ... At first, I often agreed to have sex when I did not want to, and that was generating a lot of anger in me (Camila, 29 years old)

However, several acknowledged that the social pressure to fulfill the role of wife generated that they felt obliged to respond sexually to their partners despite their pain: "I feel that I can no longer answer him equally, I can no longer fulfill my husband as a woman; that's frustrating for me, very much" (Angélica, 41 years old)

Many said they felt that their intimate and sex life was more pleasant and warm in affective terms than before being diagnosed with fibromyalgia, as their partners were more delicate to avoid hurting them: "now he is calm, with caresses, with kisses . . . It's delicious. When we can we make love ... He makes me feel loved, and that helps me a lot with my pain" (Carmen, 57 years old). With the appearance of the disease, greater importance was given to the fact that both members of the couple feel pleasure. In these cases, the pleasure was not linked to intercourse and the genital, but to the stimulation of their erogenous zones. At this point, the communication turned out to be a tool that helped both to feel pleasure and adjust to the new conditions: "sexuality for me before was from the genital, that is, from intercourse; we did not worry about what we felt ... Now we explore ourselves, we talk, we laugh, we try things" (Gloria, 45 years old).

Participants mentioned that when they had sex, pain coexisted along with pleasure. However, during these sexual encounters they tried to connect more with pleasure than with pain: "in the middle of the activity you start to feel pain . . . I try to endure the pain, but when the act ends, it seems that I had run a marathon!" (Natalia, 32 years old). Some expressed that after being diagnosed they had given greater importance to the previous stimulation, although this did not always end in an intercourse act. They also affirmed that the disease allowed them to discover the importance of the preliminary sexual game, to stimulate desire and to explore their senses.

On the other hand, part of them felt shame and fear of being judged if they talked with their social environment about their difficulties in responding sexually to their partners: "I decided not to say anything because I do not want to generate comments that I cannot answer my partner . . . I am very sorry to tell another person this, for me it is a topic that is not touched" (Angélica, 41 years old). They highlighted, in the same way, that sexuality was a topic that was discussed infrequently with health professionals and that when it was treated it was approached with resistance and discomfort.

\section{Strategies of Sexual Adjustment}

One of the strategies that couples used to manage sexual relations was to postpone these encounters until the intensity of the pain diminished: "we understood that we could not always have relationships, that we could when the pain was bearable... He understood it and we try to be together when we can" (Lina, 54 years old). At the time when they were in relationships and felt pain, many avoided paying attention to this sensation and decided to concentrate solely on pleasure. To counteract these pains, they decided to adopt positions that would be comfortable and pleasant: "many times you want to try things, but when you have fibromyalgia it hurts when you turn around, you get cramps ... There are certain positions that I cannot stand, so we decided to explore which ones generated us more pleasure" (Patricia, 43 years old).

Over time, they gave higher priority to preliminary play and sensory stimulation as a strategy to increase desire: "we understood that we should look for other ways, that we should explore our bodies, and that's how we started trying to have relationships more smoothly, with much more love. With that, we got that I felt more comfortable, that I enjoyed more" (Camila, 29 years old). Another strategy they used as partners was to use lubricants to reduce genital pain: "we bought lubricants because I was feeling pain when having sex, not that I had vaginismus because the vagina did not have contractions, but it was really dry" (Marta, 45 years old). 
As can be seen in Figure 1, the results of this research allow us to identify that the implications that the disease can have on relationships can vary depending on factors: (a) personal, such as age, educational level, economic situation, personality characteristics, beliefs about the disease, intensity and interference of pain, coping styles and emotional changes; (b) contextual, such as perceived social support, access to the health system, availability of resources and cultural influences; and (c) of the couple, such as relationship time, family structure, leisure activities, perception of the relationship, type of partner support and communication skills.

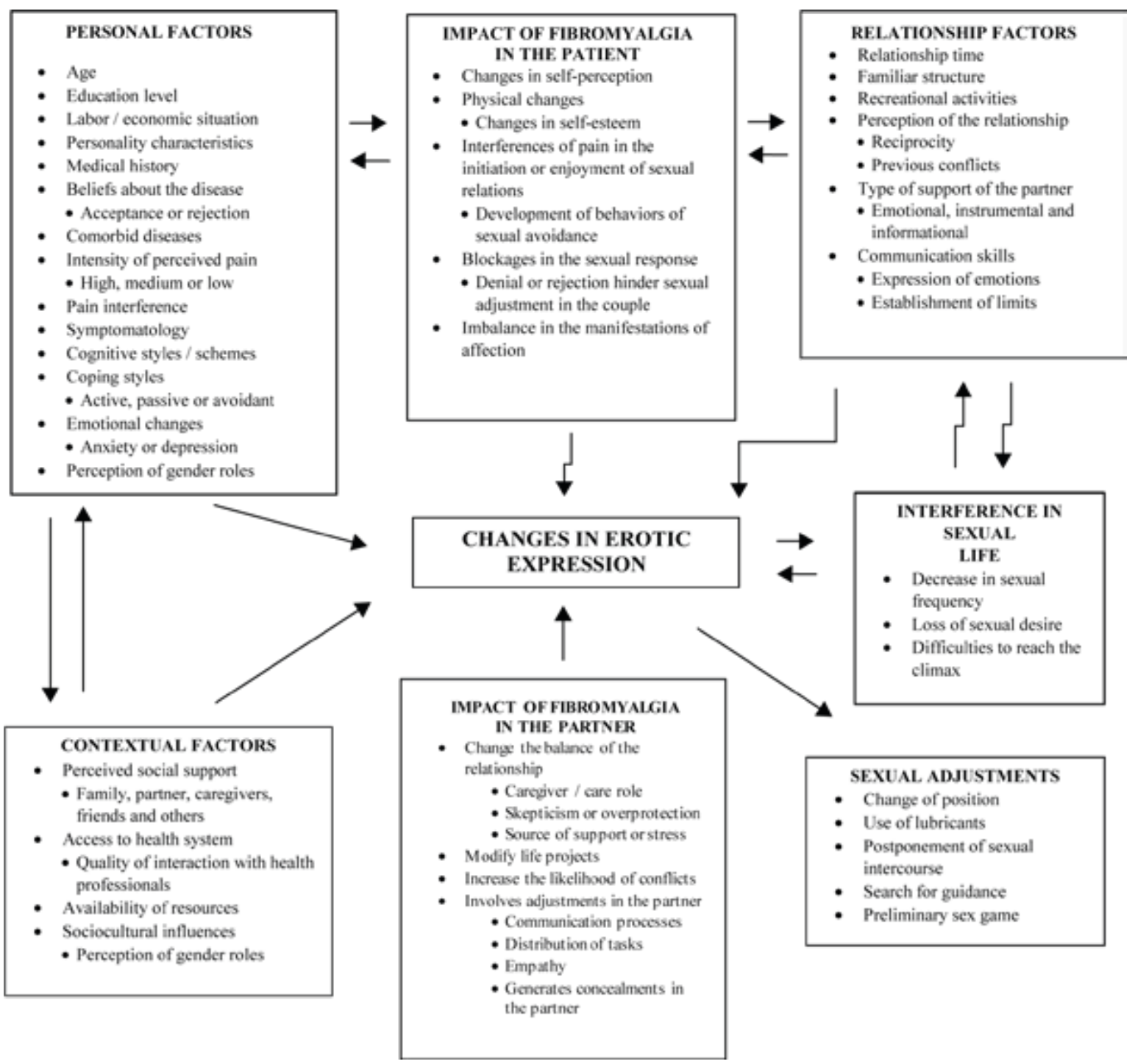

Figure 1. Dynamics of reconfiguration of erotic expression in women with fibromyalgia.

\section{Discussion}

The main objective of this research was to describe the changes in erotic expression in women with fibromyalgia. To achieve this, this work sought to know the role of the disease in the couple's relationship, understand the changes in the erotic expression as a result of diagnosis and identify the strategies used by the couple to deal with changes in their sex lives. The analysis of the stories allowed to understand the meaning that this group of women build in relation to their life stories, their interactions and the experience of the disease.

When a chronic disease breaks into the life of a couple, there is a possibility that changes in intimacy, trust and communication may occur in the relationship (GarcíaPadilla et al., 2003). In this research it was found that couples with greater stability and better communication levels had more tools to adjust to the disease than those who reported crisis prior to diagnosis (García-Padilla et al., 2003). In 
the latter, the appearance of fibromyalgia was presented as an experience that potentiated the existing conflicts in the relationship. Although the disease generated conflicts in all couples, in relationships with a history of conflict and low adjustment capacity, these changes became barriers that interfered significantly in the dynamics of their relationship.

As a result of the disease, the couple begins to live a transition process between life before and after the diagnosis (Ericksson \& Svedlund, 2006). Since the first symptoms are manifested, couples begin to experience a gradual process of grief that directly impacts their daily life and identity. When diagnosed, the partners understood the participants better and began to accept their new condition or preferred to deny the changes that had taken place. In this process both parties of the dyad had to adapt to the changes in the different areas of their lives, accept the disease and experience grief. The fluctuation of the symptoms generated changes in communication processes, the establishment of roles, the distribution of responsibilities as a couple and erotic expression. These alterations in the interaction gave rise to some forms of conflictive or adaptive relationship. The forms of conflicting relationship tended to occur when one of the members of the dyad resisted the changes that emerged in any of these areas. On the contrary, the shared coping of the disease strengthened the link (Ericksson \& Svedlund, 2006; Schlesinger, 1996; Söderberg et al., 2003).

The understanding and accompaniment of partners in pain allowed the participants to validate their existence and the subjective experience of the disease (Juuso et al., 2014). In these couples a common language was produced that allowed them to process together the experience of the disease, exchange words and gestures and share unpleasant emotional states such as pain and frustration (Rodham et al., 2010). Regarding communication, it was found that after being diagnosed many were reluctant to express their emotions and needs to their partners for fear of rejection. The inconsistencies they perceived between the way their partners behaved and the expectations they placed in them contributed to their decision to reserve the disease. This defensive attitude meant that, frequently, their partners felt rejected without understanding the reason. However, when they began to express their needs openly, their partners could understand their demands and act in accordance with them, which meant a significant change in the way in which both parts of the dyad adjusted to the disease (García-Padilla et al., 2003).

In agreement with the study by Del Rio-Gonzálezetal.(2014) it was found that the participants tended to perceive that they lost part of their physical, intellectual or sensory autonomy. However, when they felt that their partners helped them unnecessarily or showed excessive compassion for their complaints, many felt underestimated, weak and dependent It was also found that some participants interpreted the overprotection of their partners as a reminder of pain, fragility and dependence (Schlesinger, 1996). Regarding overprotection, it was identified that the partner focused on her well-being and assumed the role of the caregiver while she played the role of the sick
(Kool et al., 2006; Rodham et al., 2010; Schlesinger, 1996; Söderberg et al., 2003). This meant that they experienced a loss of freedom in the relationship, as the partner should be available to ensure their health and they felt that they needed the support of the other to perform certain activities. This dynamic ended up overwhelming the main caregiver and increasing the sensation of disability. To avoid being considered fragile, many participants preferred to avoid talking about their symptoms.

In other cases, silencing pain, as well as being a way to protect themselves from the incomprehension of others, was a way of caring for the partner. Refusing to talk about pain was a way to establish self-control over the disease and not to wear down their partner (Paulson et al., 2003). In general terms, fibromyalgia was perceived as a milestone in her life that marked a before and after in her sex life. The onset of the disease imposed a limit on their bodies that directly affected the way they lived intimacy. In accordance with the approaches of Söderberg et al. (2003) the sex life stopped being under their control to depend on the magnitude and variability of the symptoms. This did not mean that they and their partners could not build a different way of living their sexuality, but that after the disease it was necessary that they recognize the new conditions of life and make adjustments to adapt.

In the participants who perceived pain as inevitable, invincible or uncontrollable, pain became a central issue that interfered with their sex life (Del Rio-González et al., 2014; Osborn \& Smith, 2006). In this sense, many preferred to avoid sexual relations because their resources focused more on restricting activities to avoid pain than focusing on those that generated pleasure. The genital and corporal pain that occurred before, during and after intercourse influenced the posture they assumed in relation to their sex life (Prins et al., 2006; Sanabria \& Gers, 2019; Shaver et al., 2006; Tikiz et al., 2005; Ülker et al., 2013). As a result, in many cases sexual encounters were evoked as a painful act that increased the symptoms of the disease (Prins et al., 2006).

Schlesinger (1996) argued that the sexuality of women with fibromyalgia involved the coexistence of opposite sensations such as pain and enjoyment. As in other research, it was found that in the participants the view that their body only caused pain and discomfort was enriched by the representation that their body could also produce pleasure and satisfaction (Blázquez et al., 2009; Schlesinger, 1996). The resignification of their own body required that they accept and integrate the limitations and changes. Otherwise, they could nullify their entire sexual and erotic life as a way of disconnecting from their own body (Osborn \& Smith, 2006).

In agreement with the findings of García-Padilla et al. (2003), it was identified that the lack of initiative and apathy in this area reflected the lack of autonomy experienced in different areas of life. The change of roles of the couple possibly forged a way of relating that extended to all areas of the relationship (Kool et al., 2006; Schlesinger, 1996; Söderberg et al., 2003). In the sexual sphere, many gave their partners the initiative and the approach of alternatives. This imbalance in roles relegated the responsibility of pleasure and initiative to a single 
member of the relationship, a situation that caused several to experience intimate encounters as an obligation. In a certain way, partners may feel obliged to provide them with pleasure. One possibility is that the lack of perceived capacity reinforced the idea that they were incapable of being agents of their own pleasure. The idea that their body only reminded them of pain and disease made it difficult for them to reconcile with sensations of pleasure.

For other participants, sexual relations became a sacrifice to which they submitted in silence for love and gratitude towards their partners. Although this long-term behavior could generate anger, in the short term it mitigated the guilt that arose from the feeling of not matching the expectations of their partners and social conventions (García-Padilla et al., 2003). Those who perceived that the sexual act was a necessary duty in order not to lose the partner presented greater difficulties to experience pleasure (Blázquez et al., 2009; García-Padilla et al., 2003; Schlesinger, 1996). The fear that was generated by avoiding a direct confrontation on the subject, caused that they dilated the intimate encounter. The importance that their partners give to their sexual performance could contribute to making it more difficult for them to communicate their difficulties (Loaring et al., 2015).

In addition, at the time they explained how the disease interfered with sexual desire and the experience of pleasure, the partner could become a support network. In this order of ideas, when the limits of the participants were clear, their partners accepted them more easily than when they did not offer explanations about their attitude. As in other research, it was found that when the members of the couples discussed their respective points of view, they began to propose solutions that allowed them to rethink their sex life (Blázquez et al., 2009; García-Padilla et al., 2003; Loaring et al., 2015). The linkage with the partner in this dimension demanded negotiations and learning new erotic ways of relating.

In this sense, many participants established sexual limits with their partners and agreed to have relationships only when the intensity of the symptoms was minimal (Schlesinger, 1996). Other adjustments that were presented were the search for comfortable positions and the use of lubricants to reduce genital pain. To adjust to the disease, the partners claimed to give greater importance to the previous stimulation than to the intercourse act. Although there was a decrease in the frequency with which they had sex with their partners, many said they felt sexually more satisfied. Paradoxically, the enrichment of erotic expression and pleasure was simultaneous to the changes that resulted from the disease such as decreased sexual desire, arousal, frequency and lubrication. The restrictions generated by fibromyalgia led some couples to use creativity to change their activities and conceptions about sexuality.

Blázquez et al. (2009), García-Padilla et al. (2003) and Ostrander (2009) stated that sexual adjustment requires couples to change the traditional sexuality centered on intercourse and orgasm for a sexuality that includes the sensuality of the whole body, the expression of emotions and intellectual intimacy. In this research, it was found that when rethinking their sexual dynamics, many participants were able to detach from the guilt they felt in not responding in this area as before the diagnosis (Ostrander, 2009). The sexual adjustments involved, in the first place, a recognition of the participants on their body and, secondly, an accompaniment to their partners to identify new ways of approaching their body and stimulating it. As in the study by Ostrander (2009), part of the participants said they enjoyed their intimate encounters more because both they and their partners were more attentive to their respective physical and emotional needs.

These results suggest that the impact of fibromyalgia on the erotic expression of the participants depends more on the position that the woman assumes in the face of pain than on the symptoms of the disease. Similarly, it was found that the participants lived the changes in erotic expression like the way they dealt with the impact of the disease in their daily lives. Thus, when they visualized pain as catastrophic and uncontrollable, they avoided sexual intercourse to protect themselves from pain. On the other hand, when they conceived their pain as controllable, they used to look for activities that gave them pleasure as a partner and found creative solutions to counteract pain and enhance sexual pleasure. Regarding the position they assumed in front of their partner, it was identified that when women assumed a more active role within the relationship, they were also able to be agents of their own pleasure, make adjustments considering the new conditions and share their point of view. In this context, women felt more empowered to express to their partners when they wanted to have sexual relations or not and how they wanted these intimate encounters to be (Ostrander, 2009). In the opposite case, the participants lived the sexual act as an obligation, a sacrifice or an imposition of the partner in front of which they had to adjust.

Although the study participants were women of different ages and socioeconomic levels, the homogeneity of the population limited the generalization of these findings to other disease conditions and social groups. Another limitation of this research was that the influence of comorbidity or climacteric was not considered, which is why the transferability of the results should consider that these aspects that were not considered can influence the erotic expression.

It is increasingly necessary that the interventions of professionals consider the importance of erotic expression and the potential of patients with chronic diseases to feel pleasure despite the pain. In the same way, it is important to offer tools to health personnel that make it possible to address this area of the patient's life in a sensitive manner and to recognize their sexual rights and reproductive rights. In future research it is recommended to interview both members of the dyad to obtain a perspective of the shared experience of erotic expression in the context of a chronic disease (Ericksson \& Svedlun, 2006; Rodham et al., 2010; Sörderberg et al., 2003). Other 
works could also address changes in erotic expression in women who are not in a relationship. Finally, it would be interesting to carry out cross-cultural studies that can generate important contributions at a global level for the analysis and treatment of the phenomenon in patients and couples who enroll in other social contexts.

\section{References}

Ambler, N., Williams, A. C., Hill, P., Gunary, R., \& Cratchley, G. (2001). Sexual difficulties of chronic pain patients. Clinical Journal of Pain, 17(2), 138-145. doi:10.1097/00002508-200106000-00006

Bazzichi, L., Giacomelli, C., Rossi, A., Sernissi, F., Scarpellini, P., Consensi, S., \& Bombardieri, S. (2012). Fibromyalgia and sexual problems. Reumatismo, 64(4), 261-267. doi:10.4081/reumatismo.2012.261

Blázquez, A., Alegre, J., \& Ruiz, E. (2009). Women with chronic fatigue syndrome and sexual dysfunction: Past, present and future. Journal of Sex and Marital Therapy, 35(5), 347-359. doi:10.1080/00926230903065179

Del Rio-González, E., García-Palacios, A., \& BotellaArbona, C. (2014). Calidad de vida en fibromialgia: Influencia de factores físicos y psicológicos [Quality of life in fibromyalgia: Influence of physical and psychological factors]. Psicología Conductual, 22(1), 19-35. Retrieved from http://repositori.uji.es/ $\mathrm{xmlui} /$ bitstream/handle/10234/120484/63141. pdf? sequence $=1$ \&isAllowed $=\mathrm{y}$

Ericksson, M., \& Svedlund, M. (2006). 'The intruder': Spouses' narratives about life with a chronically ill partner. Journal of Clinical Nursing, 15(3), 324-333. doi:10.1111/j.1365-2702.2006.01290.x

Ferreira, C. C., Mota, L. M. H., Oliveira, A. C. V., Carvalho, J. F., Lima, R. A. C., Simaan, C. K., . . Santos-Neto, L. (2013). Frequency of sexual dysfunction in women with rheumatic diseases. Revista Brasileira de Reumatologia, 53(1), 35-46. doi:10.1590/S0482-50042013000100004

García-Padilla, D. R., García-Padilla, M. P., Ballesteros de Valderrama, B. P., \& Novoa-Gómez, M. M. (2003). Sexualidad y comunicación de pareja en mujeres con cáncer de cérvix: Una intervención psicológica [Sexuality and couple communication in women with cervical cancer: A psychological intervention]. Universitas Psychologica, 2(2), 199-214. Retrieved from https://www.redalyc.org/articulo.oa?id=64720209

Gers, M., \& Sanabria, J. P. (2017). Cambios en la expresión erótica en mujeres diagnosticadas con fibromialgia [Changes in erotic expression in women diagnosed with fibromyalgia (degree's dissertation)] (Final Degree Work, Pontificia Universidad Javeriana de Cali, Cali, Colombia). Retrieved from http://vitela.javerianacali.edu. co/handle $/ 11522 / 8386$ ?show=full
Hernández-Petro, A. M., \& Cardona-Arias, J. A. (2014). Sistematización de las investigaciones sobre calidad de vida relacionada con la salud en fibromialgia, 2004-2014 [Systematization of research on health-related quality of life in fibromyalgia, 2004-2014]. Archivos de Medicina, 10(1), 22. doi:10.3823/1233

Juuso,P.,Skar,L.,Olsson,M.,\&Söderberg,S.(2014).Meanings of being received and met by others as experienced by women with fibromyalgia. Qualitative Health Research, 24(10), 1381-1390. doi:10.1177/1049732314547540

Kalichman, L. (2009). Association between fibromyalgia and sexual dysfunction in women. Clinical Rheumatology, 28(4), 365-369. doi:10.1007/s10067-009-1093-3

Kool,M. B., Woertman, L., Prins, M.A., Van Middendorp,H., \& Geenen, R. (2006). Low relationship satisfaction and high partnerinvolvement predictsexual problems of women with fibromyalgia. Journal of Sex \& Marital Therapy, 32(5), 409-423. doi:10.1080/00926230600835403

Loaring, J. M., Larkin, M., Shaw, R., \& Flowers, P. (2015). Renegotiating sexual intimacy in the context of altered embodiment: The experiences of women with breast cancer and their male partners following mastectomy and reconstruction. Health Psychology, 34(4), 426-436. doi:10.1037/hea0000195

Orellana, C., Casado, E., Masip, M., Galisteo, C., Gratacós, J., \& Larrosa, M. (2008). Sexual dysfunction in fibromyalgia patients. Clinical and Experimental Rheumatolog, 26(4) 663-666. Retrieved from http://www.clinexprheumatol.org/article.asp?a $=3423$

Osborn, M., \& Smith, J. (2006). Living with a body separate from the self. The experience of the body in chronic benign low back pain: An interpretative phenomenological analysis. Scandinavian Journal of Caring Sciences, 20(2), 216-222. doi:10.1111/j.1471-6712.2006.00399.x

Ostrander, N. (2009). Sexual pursuits of pleasure among men and women with spinal cord injuries. Sexuality and Disability, 27(1), 11-19. doi:10.1007/s11195-008-9103-y

Paulson, M., Norberg, A., \& Söderberg, S. (2003). Living in the shadow of fibromyalgic pain: The meaning of female partners' experiences. Journal of Clinical Nursing, 12(2), 235-243. doi:10.1046/j.1365-2702.2003.00733.x

Prins, M, A., Woertman, L., Kool, M. B., \& Geenen, R. (2006). Sexual functioning of women with fibromyalgia. Clinical and Experimental Rheumatology, 24(5), 555-561. Retrieved from https://www.clinexprheumatol.org/article.asp? $\mathrm{a}=2960$

Rodham, K., Rance, N., \& Blake, D. (2010). A qualitative exploration of careers' and 'patients' experiences of fibromyalgia: One illness, different perspectives. Musculoskeletal Care, 8(2), 68-77. doi:10.1002/msc.167 
Ryan, S., Hill, J., Thwaites, C., \& Dawes, P. (2012). Assessing the effect of fibromyalgia on patients' sexual activity. Nursing Standard, 23(2), 35-41. doi:10.7748/ns2008.09.23.2.35.c6669

Sanabria, J. P., \& Gers, M. (2018). Implications of chronic pain on the quality of life of women with fibromyalgia. Psicologia em Estudo, 23, 81-9. doi: 10.4025/psicolestud.v23.38447

Sanabria, J. P., \& Gers, M. (2019). Repercusiones del dolor crónico en las dinámicas de pareja: perspectivas de mujeres con fibromialgia [Repercussions of Chronic Pain in Couple Dynamics: Perspectives of Women with Fibromyalgia]. Revista Colombiana de Psicología, 28(2). doi: 10.15446/rcp.v28n2.71021

Schlesinger, L. (1996). Chronic pain, intimacy, and sexuality: A qualitative study of women who live with pain. The Journal of Sex Research, 33(3), 249-256. doi:10.1080/00224499609551841

Shaver, J. L., Wilbur, J., Robinson, F. P., Wang, E., \& Buntin, M. S. (2006). Women's health issues with fibromyalgia syndrome. Journal of Women's Health, 15(9), 1035-1045. doi:10.1089/jwh.2006.15.1035

Söderberg, S., Strand, M., Haapala, M., \& Lundman, B. (2003). Living with a woman with fibromyalgia from the perspective of the husband. Journal of Advanced Nursing, 42(2), 143-150. doi:10.1046/j.1365-2648.2003.02597.x

Soriano, J., Monsalve, V., Gómez-Carretero, P., \& Ibáñez, E. (2012). Vulnerable personality profile in patients with chronic pain: Relationship with coping, quality of life and adaptationtodisease.InternationalJournalofPsychological Research, 5(1), 42-51. doi:10.21500/20112084.748

Tawadros, A. E., Udeoji, D., Awad, M., Castro-Abeger, A., Nguyen, T., Bensoussan, J.-C., \& IsHak, W. W. (2013). Quality of life in patients with fibromyalgia. International Journal of Clinical Psychiatry and Mental Health, 1(1), 1-17. doi:10.12970/2310-8231.2013.01.01.1

Tikiz, C., Muezzinoglu, T., Pirildar, T., Taskn, E. O., Frat, A., \& Tuzun, C. (2005). Sexual dysfunction in female subjects with fibromyalgia. Journal of Urology, 174(2), 620-630. doi:10.1097/01.ju.0000165155.33511.eb

Triviño-Martínez, A., Solano-Ruiz, M. C., \& Siles-González, J. (2014). La cronicidad de la fibromialgia: una revisión de la literatura [The chronicity of fibromyalgia:Areview of the literatura]. Enfermería Global, 13(35), 273-292. Retrieved fromhttp://scielo.isciii.es/scielo.php?script $=$ sci_ arttext\&pid $=$ S1695-61412014000300016

Ülker, R. N., Çakır, T., Yalçınkaya, S., Demirdal, Ü. S., \& Toraman, N. F. (2013). Assessment of sexual dysfunction in patients with fibromyalgia syndrome. Turkish Journal of Osteoporosis, 19, 65-68. doi:10.4274/tod.29981
Willig, C. (2013). Introducing qualitative research in psychology. New York, NY: McGraw Hill Education.

Yilmaz, H., Yilmaz, S. D., \& Erkin, G. (2012). The effects of fibromyalgia syndrome on female sexual function. Sexuality and Disability, 30(1), 109-113. doi:10.1007/s11195-011-9229-1

Yilmaz, H., Yilmaz, S. D., Polat, H. A. D., Salli, A., Erkin, G., \& Ugurlu, H. (2012). The effects of fibromyalgia syndrome on female sexuality: A controlled study. The Journal of Sexual Medicine, 9(3), 779-785. doi:10.1111/j.1743-6109.2011.02619.x

Juan Pablo Sanabria Mazo is a Researcher of the Facultad de Humanidades y Ciencias Sociales at Pontificia Universidad Javeriana, Cali, Colombia.

Mariana Gers Estrada is a Researcher of the Facultad de Humanidades y Ciencias Sociales at Pontificia Universidad Javeriana, Cali, Colombia.

\section{Authors' Contribution:}

All authors made substantial contributions to the conception and design of this study, to data analysis and interpretation, and to the manuscript revision and approval of the final version. All the authors assume public responsability for content of the manuscript.

Received: Mar. 07, 2017

1st Revision: May. 07, 2017

2nd Revision: Apr. 27, 2018

Approved: May. 01, 2018

How to cite this article:

Sanabria, J.P., \& Gers, M. (2019). Changes in erotic expression in women with fibromyalgia. Paidéia (RibeirãoPreto), 29, e2923. doi:http://dx.doi.org/10.1590/1982-4327e2923 